\title{
Alternative Finishing Process for Poly(ethylene terephthalate)(PET) Tire Cord using Atmospheric Plasma
}

\author{
Sam Soo Kim, Eun Young Song, Dong Lyun Cho', Jun Park ${ }^{1}$, \\ Sung Ho Park ${ }^{2}$ and Jaewoong Lee ${ }^{3, \dagger}$ \\ School of Textiles, Yeungnam University, Gyeongsan, 712-749, Korea \\ ${ }^{1}$ School of Applied Chemical Engineering, Chonnam National University, Gwangju, 500-757, Korea \\ ${ }^{2}$ Kolon Industries, Inc., Gumi, 730-030, Korea \\ ${ }^{3}$ Korean Intellectual Property Office, Daejeon, 302-701, Korea
}

(Received: October 26, 2010/Revised: November 25, 2010/Accepted: December 13, 2010)

\begin{abstract}
Poly(ethylene terephthalate)(PET) tire cord has relatively lower adhesion properties caused by limited reacting sites. In order to improve the adhesion force between PET tire cord and rubber, an additional process to activate surface of PET has been employed. Atmospheric plasma was used to substitute the chemical finishing process of PET tire cord as a green dipping process. Contact angle was measured to confirm surface change of PET after plasma treatment. The treated PET tire cords with/without resorcinol-formaldehyde-latex(RFL) and unvulcanized rubber were vulcanized in a testing mold at $160^{\circ} \mathrm{C}$. After atmospheric plasma treatment of PET tire cord, adhesion force was somewhat increased under some conditions.
\end{abstract}

Keywords: PET tire cord, atmospheric plasma, adhesive, green dipping, surface modification

\section{Introduction}

Among textile tire cords, nylon and lyocell tire cords have used resorcinol-formaldehyde-latex(RFL) as an adhesive for a single dip process. This can be attributed to hydrophilic characteristics and their abundant reacting groups such as amine groups $\left(-\mathrm{NH}_{2}\right)$ and hydroxyl groups(-OH). However, poly (ethylene terephthalate)(PET) tire cords possess relatively hydrophobic characteristics and have $-\mathrm{OH}$ and $-\mathrm{COOH}$ groups at the end of each polymer-chain side. Thus, RFL could not provide sufficient adhesion between PET and rubber ${ }^{1,2}$. In order to use PET for tire cords, an additional dipping step has been employed allowing the surface of the PET tire cord to be activated by epoxy adhesives such as polyglycidyl ether or Pexul which is a 2,6-bis (2',4'-dihydroxyphenyl-methyl)-4-chlorophenol. These materials can enhance reacting sites of PET which result in sufficient adhesion force with tire rubber $^{3-8)}$. In case of Pexul, ammonium hydrox$\operatorname{ide}\left(\mathrm{NH}_{4} \mathrm{OH}\right)$ is used to stabilize the Pexul solution. Due to the toxicity of ammonium hydroxide, the ex posure to this material in tire cord manufacturing plant is harmful process to laborers. Epoxy/ Isocyanate dip is an alternative to Pexul and can provide a cleaner process than Pexul dip; however, epoxy and isocyanate are also harmful chemicals for the environment. Furthermore, both Pexul and Epoxy/Isocyanate dip processes consume large amount of energy to generate heat for the activation of PET tire cord. After the tire cord finishing process, the waste products including toxic chemicals and latex require waste treatment which means that additional cost for purification is needed.

The ideal case for tire cord dipping might be low chemical and energy consumption which result in low carbon dioxide $\left(\mathrm{CO}_{2}\right)$ generation. In terms of PET surface modification, plasma treatments have been employed intensively ${ }^{9-15)}$. However, little research has been done with atmospheric plasma treatment for PET tire cords to substitute the Epoxy/ Isocyanate dip. In this research, atmospheric plasma was studied to substitute Epoxy/Isocyanate dip as a green process. PET films and PET tire cords were treated with atmospheric plasma under air or oxygen

${ }^{\dagger}$ Corresponding author. Tel.: +82-42-481-8716; Fax.: +82-42-472-3558; e-mail: leejaew@hotmail.com

(c)2010 The Korean Society of Dyers and Finishers 1229-0033/2010-12/300-305 
purge and then contact angle of treated samples was measured. Adhesion forces between PET tire cord and tire rubber were also investigated.

\section{Experimental}

\subsection{Materials}

Pure, unmodified PET film of $100 \mu \mathrm{m}$ thickness and 1500 denier/2ply PET tire cords were supplied by Kolon Industries. The tensile strength and strain of the PET raw cord were $24 \mathrm{kgf}$ and $16 \%$, respectively. The resorcinol-formaldehyde-latex used was also produced by Kolon and was used within $48 \mathrm{~h}$ after preparation.

\subsection{Plasma treatment}

In order to enhance the adhesion force between PET and RFL, ambient air and oxygen were employed as a gas for plasma treatment(NOWPLASMA Co. LTD, Model NW-PRS8010S). Discharge power and treatment time were varied from 125 to $500 \mathrm{~W}$ and 20 to $240 \mathrm{sec}$, respectively.

\subsection{Measurement of hydrophilicity}

The contact angle of the PET film was measured using a contact angle tester(ERMA, Model G-1). Since it has some difficulties to assess the contact angle of PET tire cords which have uneven surface of the twisted multi-filaments, in order for hydrophilicity of the PET tire cord, methylene blue solution was employed. A $1 \mathrm{~cm}$ section of the edge of $40 \mathrm{~cm}$ PET tire cord was soaked into the solution, and the length of methylene blue on the PET tire cord was measured after $1 \mathrm{~min}$. The different length of methylene blue on PET tire cords before and after the plasma treatment represent the change of hydrophilicity of the PET tire cord.

\subsection{Adhesion force}

Plasma treated PET tire cords were coated with $\mathrm{RFL}$ at $140{ }^{\circ} \mathrm{C}$ for $3 \mathrm{~min}$ followed by curing at 220 ${ }^{\circ} \mathrm{C}$ for $2 \mathrm{~min}$ before it was vulcanized for $8 \mathrm{~min} 45$ sec at $160{ }^{\circ} \mathrm{C}$ with unvulcanized rubber in a mold. The adhesion force of the samples was measured with a universal materials testing machine(Instron Model 1122) at $22{ }^{\circ} \mathrm{C}$ and $65 \%$ relative humidity af ter conditioning for $24 \mathrm{~h}$. The crosshead speed was $100 \mathrm{~mm} / \mathrm{min}$. The styrene-butadiene rubber(SBR) compounding recipe which was used for the rubber to assess adhesion force is shown in Table 1. The size and weight of vulcanized rubber sample were $75 \times 75 \times 12 \mathrm{~mm}$ and $9.8 \mathrm{~g}$ respectively. The sample for adhesion test is depicted in Fig. 1.

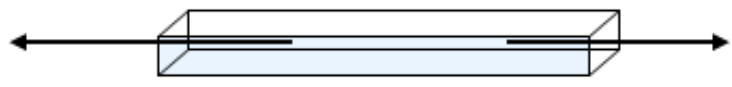

Fig. 1. Sample for adhesion test.

\section{Results and discussion}

\subsection{Hydrophilicity change after atmospheric plasma treatment}

PET films were treated with atmospheric plasma and the contact angle data of the PET films is shown in Fig. 2 and 3. The results demonstrate that the contact angle of PET film was decreased with increasing power of plasma until 260 and $248 \mathrm{~W}$

Table 1. Styrene-butadiene rubber(SBR) compounding recipe

\begin{tabular}{cccc}
\hline \multirow{2}{*}{ Blending } & Material & \multicolumn{2}{c}{ Unfilled } \\
\cline { 3 - 4 } & & $\mathrm{Phr}^{\mathrm{a}}$ & Weight(g) \\
\hline First(1st) Blending & S-SBR & 137.50 & 202.63 \\
Internal mixer & Zinc Oxide & 3.00 & 4.42 \\
$\left(120{ }^{\circ} \mathrm{C}, 50 \mathrm{rpm}\right)$ & Stearic acid & 2.00 & 2.95 \\
\hline Second(2nd) Blending & total & 142.50 & 210.00 \\
Internal mixer & sulfur & 1.50 & 2.21 \\
$\left(70{ }^{\circ} \mathrm{C}, 50 \mathrm{rpm}\right)$ & $\mathrm{CBS}^{\mathrm{c}}$ & 1.50 & 2.21 \\
\hline
\end{tabular}

Third(3rd) Blending: Two-roll mill(40 $\left.{ }^{\circ} \mathrm{C}, 8 \mathrm{rpm}, 3 \mathrm{~mm} \rightarrow 2.2 \mathrm{~mm}\right)$

${ }^{\mathrm{a}}$ Parts per hundred of rubber, ${ }^{\mathrm{b}}$ Tufdene3335(Asahi Co., Ltd.), ${ }^{\mathrm{c}} \mathrm{N}$-cyclohexyl-2-benzothiazolesulfenamide, ${ }^{\mathrm{d}}$ Diphenylguanidine 
I 302 I Sam Soo Kim · Eun Young Song · Dong Lyun Cho · Jun Park · Sung Ho Park · Jaewoong Lee

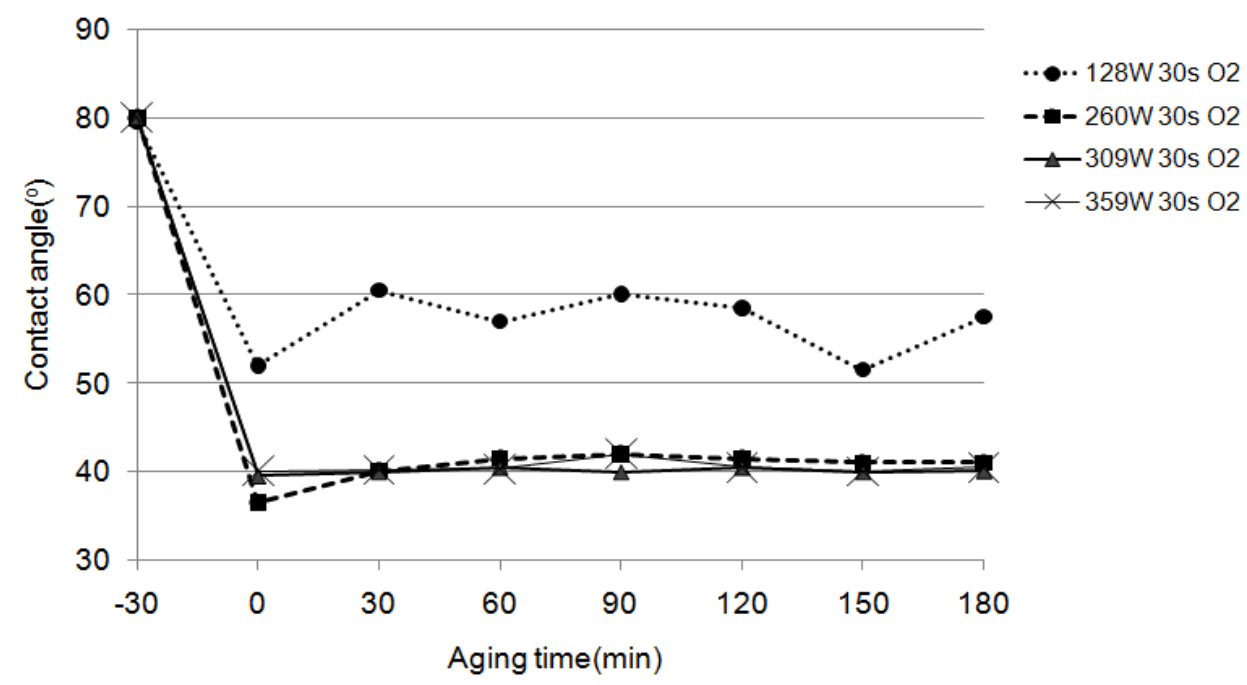

Fig. 2. Variation of contact angle of PET film under diverse discharge power in $\mathrm{O}_{2}$ according to aging time(Aging time -30 min means the contact angle before the treatment).

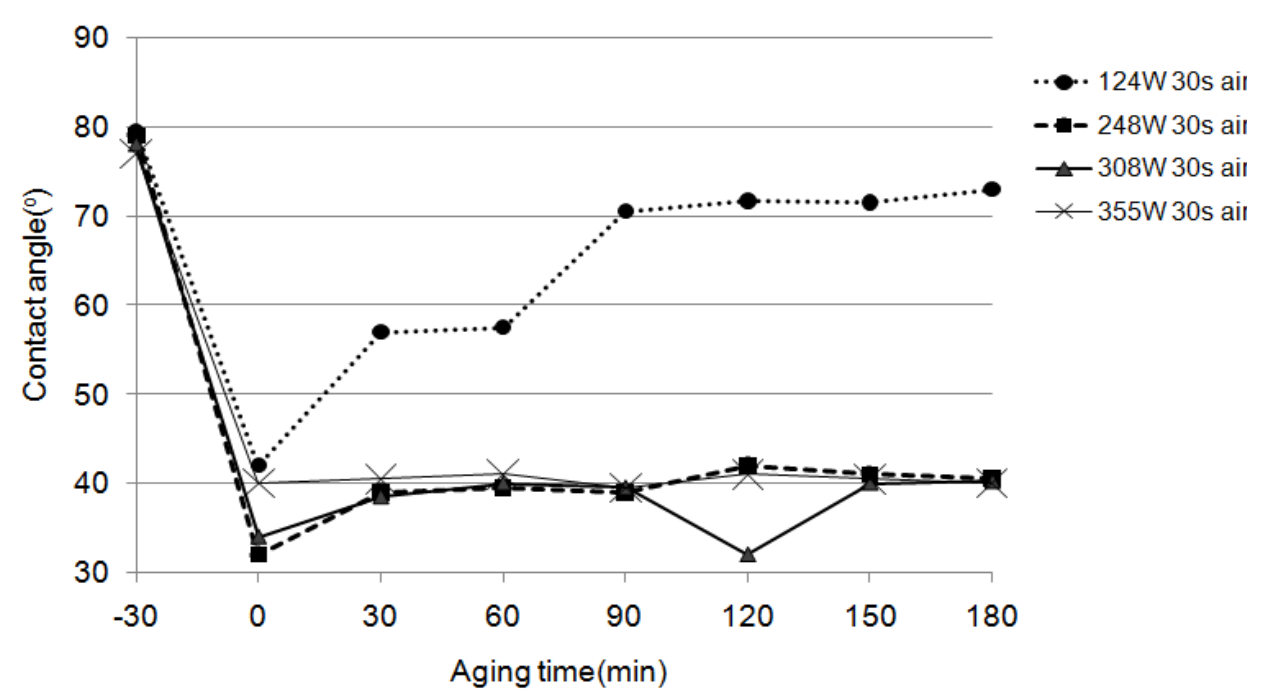

Fig. 3. Variation of contact angle of PET film under diverse discharge power in air according to aging time(Aging time -30 min means the contact angle before the treatment).

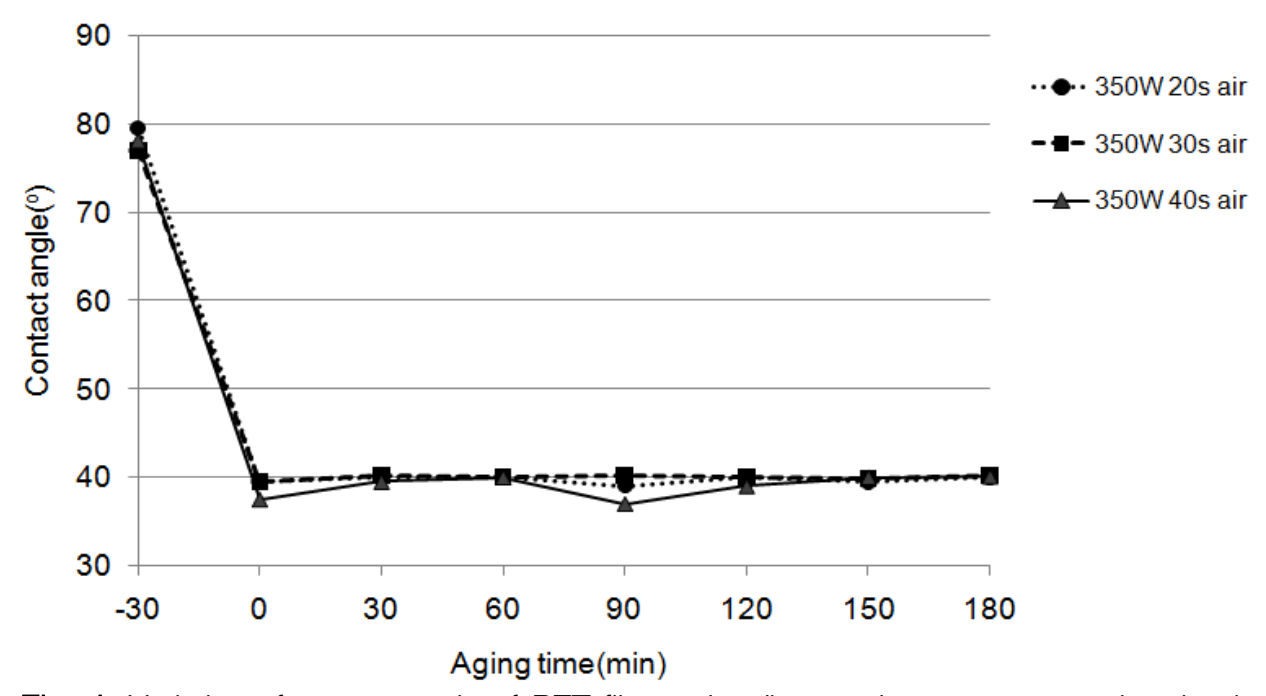

Fig. 4. Variation of contact angle of PET film under diverse plasma treatment time in air according to aging time(Aging time -30 min means the contact angle before the treatment). 
under $\mathrm{O}_{2}$ purge and ambient air, respectively. Above those power, no additional change of contact angle of PET films was detected(See Fig. 2 and 3). In case of the treated surface of PET film, aging phenomena occurred; however, the range of variation was small and stabilized in 30 60 min after plasma treatment. The PET films were also treated under different times and these results are shown in Fig. 4. As can be seen, no change was apparent for differing treatment times of 20, 30 and $40 \mathrm{sec}$. It is assumed that additional plasma treatment cause demage instead of enhancing activation sites.

\subsection{Surface change of PET tire cord after plasma treatment}

In order to measure the change of PET tire cord after plasma treatment, methylene blue was used.
The results depicted in Fig. 5 and 6, showed that untreated PET tire cord has the highest methylene blue length, whereas the PET tire cord which was treated under optimum condition for PET film, possesses relatively lower methylene blue length. However, the color of methylene blue on the plasma treated PET tire cord showed the relatively thicker methylene blue color. It is presumed that enhanced hydrophilicity of the PET tire cord after the plasma treatment results in deeper penetration of methylene blue inside the PET tire cord rather than in a higher length of methylene blue.

\subsection{Adhesion force between PET tire cord and rubber}

Optimum vulcanization time of the rubber was measured using time/torque test at $160{ }^{\circ} \mathrm{C}$ and the

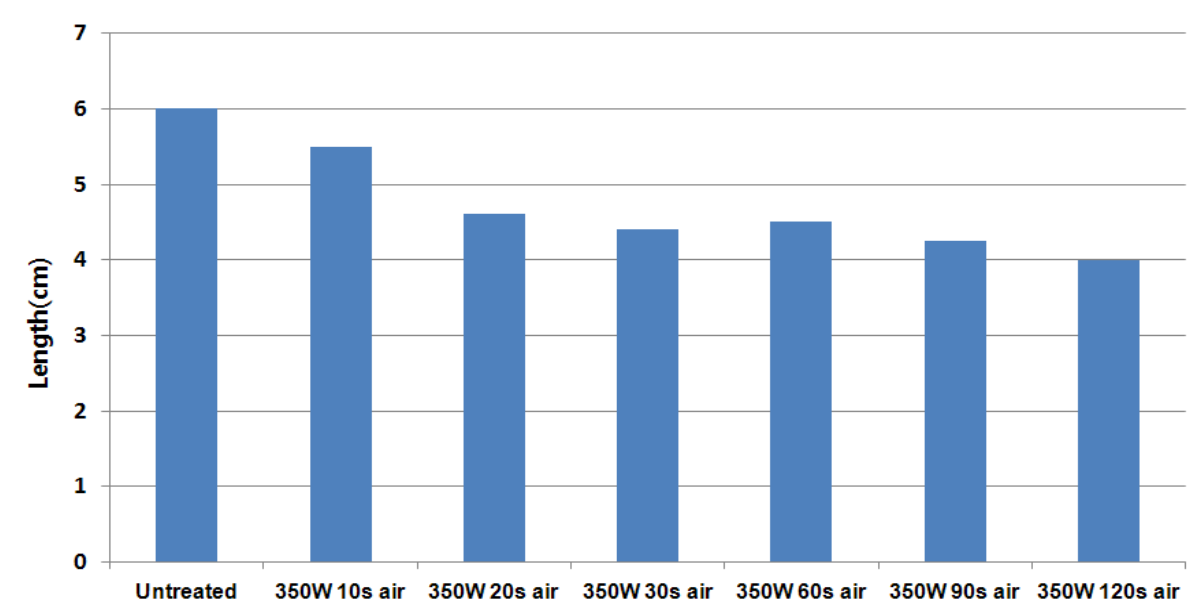

Fig. 5. The length of methylene blue on the PET tire cord after plasma treatment with air.

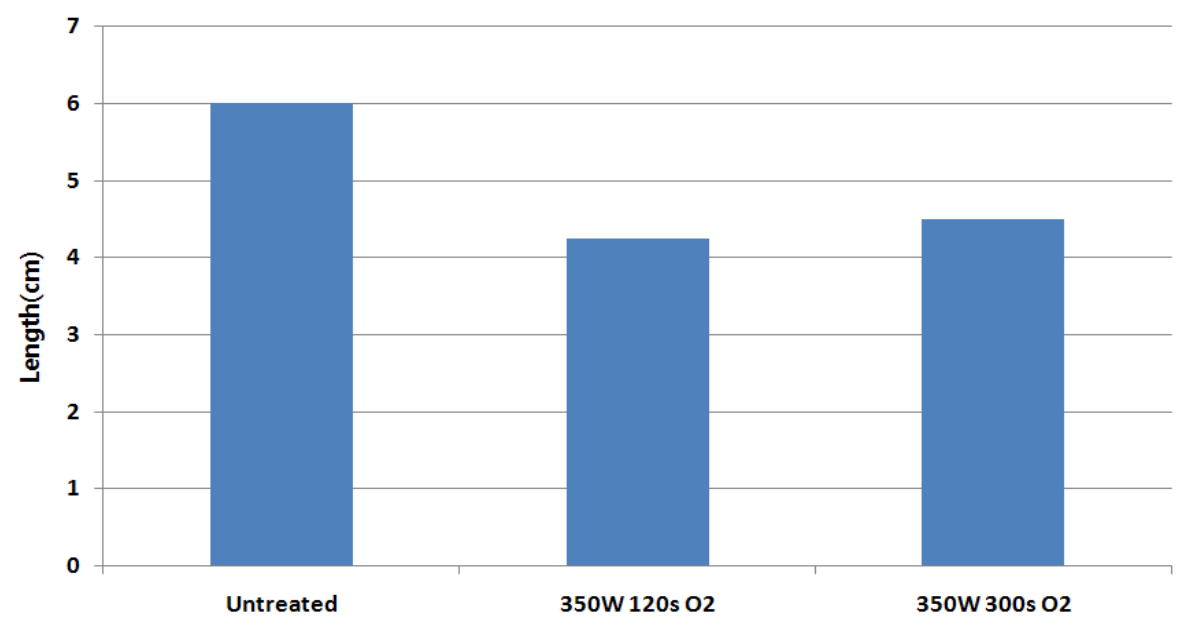

Fig. 6. The length of methylene blue on the PET tire cord after plasma treatment with $\mathrm{O}_{2}$. 
Table 2. Adhesion force between PET tire cord and rubber after atmospheric plasma treatment

\begin{tabular}{lc}
\hline \multicolumn{1}{c}{ Sample type } & Maximum stress(MPa) \\
\hline No treatment & 7.87 \\
Only RFL treatment & 9.95 \\
Plasma(350 W, air, 180 s) + RFL & 10.59 \\
Plasma(350 W, air, 240 s) + RFL & 10.59 \\
Plasma(500 W, air, 120 s) + RFL & 9.95 \\
Plasma(500 W, air, 180 s) + RFL & 8.99 \\
Plasma(350 W, O $2,180 \mathrm{~s})+$ RFL & 10.11 \\
Plasma(350 W, O $2,240 \mathrm{~s})+$ RFL & 8.35 \\
Plasma(500 W, $\left.\mathrm{O}_{2}, 120 \mathrm{~s}\right)+$ RFL & 9.31 \\
Plasma(500 W, $\left.\mathrm{O}_{2}, 180 \mathrm{~s}\right)+$ RFL & 8.99 \\
\hline
\end{tabular}

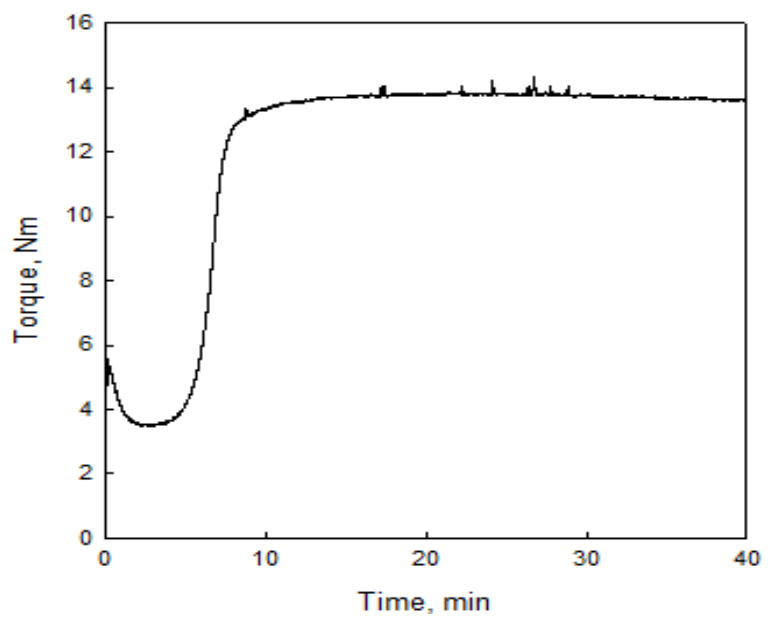

Fig. 7. Cure curve of the SBR: test sample $10.5 \mathrm{~g}$, temperature $160{ }^{\circ} \mathrm{C}$, and cure time $(\mathrm{t} 90)=8 \mathrm{~min} 45 \mathrm{sec}$.

result is shown in Fig. 7. The vulcanization was finished within $8 \mathrm{~min} 45 \mathrm{sec}$; this time was fixed as cure time $\left(\mathrm{t}_{90}\right)$ throughout the study. Adhesion force between PET tire cord and rubber after the plasma treatment is shown in Table 2. The result showed that Plasma treatment of PET tire cord with ambient air produces relatively higher adhesion forces than the treatment with oxygen. When discharge power is $350 \mathrm{~W}$ and treatment time is $180 \mathrm{sec}$, the highest adhesion force occurs. In addition, increasing the discharge power from 350 to $500 \mathrm{~W}$ actually reduces adhesion force. It implies that excessive discharge power might damage PET fiber surface rather than activating them. Since ambient air is $21 \%$ of oxygen, it is presumed that plasma treatment with air oxidized the surface of the PET fiber with less damage than that caused by oxygen plasma at a longer treatment time.

\section{Conclusions}

Atmospheric plasma treatment with $\mathrm{O}_{2}$ and ambient air enhanced hydrophilicity of the PET film surface; this activated surface was stable for up to 180 min. Enhanced hydrophilicity of the PET tire cord under atmospheric plasma treatment using ambient air resulted in increased adhesion force for SBR rubber. Thus, atmospheric plasma treatment for PET tire cords could be one substitute for conventional Pexul or Epoxy/Isocyanate dip process.

\section{Acknowledgements}

This work was supported by the Technology Innovation Program funded by the Ministry of Knowledge Economy(MKE, Korea)(No. KC000662).

\section{References}

1. R. Prikryl, V. Cech, B. Balkova, and J. Vanek, Functional Interlayers in Multiphase Materials, Surf. Coat. Technol, 174-175, 858-862(2003).

2. M. Jamshidi, F. Afshar, N. Mohammadi, and S. Pourmahdian, Study on Cord/Rubber Interface at Elevated Temperatures by H-pull Test Method, Appl. Surf. Sci., 249, 208-215(2005).

3. G. Gillberge and L. C. Sawyer, Tire Cord Adhesion-a TEM Study, J. Appl. Polym. Sci., 28, 3723-3743(1983).

4. I. L. Shmurak, N. V. Litvinova, and R. N. Mitropol'saya, Adhesive and Technology for Treating Polyester Cord, Int. Polym. Sci. Technol, 
22, 19-20(1995).

5. I. L. Shmurak, Promising Lattices for Tire Industry, Int. Polym. Sci. Technol, 23, 55-57 (1996).

6. N. A. Darwish, T. T. Nagy, G. Samay, and A. Boros, Static and Dynamic Evaluation of Adhesion of Rubber to Textile Cord, Kautsch. Gummi Kunstst, 47(17), 32-38(1994).

7. H. Hisaki, Y. Nakano, and S. Suzuki, Adhesion of Polyester Tire Cord to Rubber and Cord Strength of Polyester Improved by Using Carbohydrated VP-latex, Tire Sci. Technol (TSTCA), 19(3), 163-175(1991).

8. I. L. Shmurak, Tire Cord-to-rubber Adhesion as a Function of Interphase Interaction, Appl. Polym. Sci., 38, 436-439(1997).

9. C. Riccardi, R. Barni, E. Selli, G. Mazzone, M. R. Massafra, B. Marcandalli, and G. Poletti, Surface Modification of Poly(ethylene terephthalate) Fibers induced by Radio Frequency Air Plasma Treatment, Appl. Surf. Sci., 211, 386397(2003).

10. Y. Kondo, K. Miyazaki, K. Takayanagi, and K. Sakurai, Surface Treatment of PET Fiber by EB-irradiation-induced Graft Polymerization and Its Effect on Adhesion in Natural Rubber Matrix, Eur. Polym. J., 44, 1567-1576(2008).

11. N. V. Bhat and Y. N. Benjamin, Surface Resistivity Behavior of Plasma Treated and Plasma Grafted Cotton and Polyester Fabrics, Textile Res. J., 69(1), 38-42(1999).

12. T. Oktem, H. Ayhan, N. Seventekin, and E. Piskin, Modification of Polyester Fabrics by in Situ Plasma or Post-plasma Polymerization of Acrylic Acid, JSDC, 115, 274-279(1999).

13. T. Oktem, N. Seventekin, H. Ayhan, and E. Piskin, Modification of Polyester and Polyamide Fabrics by Different in Situ Plasma Polymerization Methods, Turk. J. Chem., 24, 275-285 (2000).

14. F. Leroux, A. Perwuelz, C. Campagne, and N. Behary, Atmospheric Air-plasma Treatments of Polyester Textile Structures, J. Adhesion Sci. Technol, 20(9), 939-957(2006).

15. U. Vohrer, M. Muller, and C. Oehr, Glowdischarge Treatment for the Modification of Textiles, Surf. Coat. Technol, 98, 1128-1131 (1998). 